\title{
Laparoscopic Entry Using Direct First Trocar Insertion without a Prior Pneumoperitoneum: A Prospective Cohort Study
}

\author{
Jawad K Shunayeh AL-Dhahiry
}

\begin{abstract}
Purpose: This study aimed to assess safety, feasibility, complications, and time of direct first trocar insertion (DFTI) with carbon dioxide $\left(\mathrm{CO}_{2}\right)$ insufflation and operating time in laparoscopic surgery.

Materials and methods: This study was a prospective cohort study (clinical original) performed at AL-Karama Teaching Hospital/College of Medicine, Wasit University, Iraq, from April 2011 to December 2017. The study enrolled 687 patients prepared for different laparoscopic procedures using direct first trocar insertion techniques for laparoscopic entry. Conversion of laparoscopic entry to Veress needle (VN) or open technique was performed when direct first trocar insertion technique failed. Recorded data were age, sex, indications for laparoscopic surgery, time of direct first trocar insertion with $\mathrm{CO}_{2}$-insufflation,operating time, and direct first trocar insertion-related complications.

Results: Direct first trocar insertion technique was successful in 684 (99.57\%) patients and failed in 3 patients when trocar entry was converted to Veress needle technique. These three patients were excluded from the statistical analysis of the study data. Demographic distribution of the patients was as follows: 90 (13.2\%) males and 594 (86.8\%) females. This study had no major complications, while minor complication rate was $1.31 \%$. Mean \pm standard deviation (SD) of direct first trocar insertion with $\mathrm{CO}_{2}$-insufflation time for males, females, and total patients was 2.32 \pm 0.57 minute $(\mathrm{m}), 1.89 \pm 0.53 \mathrm{~m}$, and $1.95 \pm 0.56 \mathrm{~m}$, respectively. $p$ value was 0.03 and was statistically significant. This study had no mortality. Conclusion and clinical significance: Direct first trocar insertion is a safe and cost-effective laparoscopic entry technique. It has a high feasibility rate, low complication rate, fast laparoscopic entry, and fast creation of pneumoperitoneum.

Keywords: Direct first trocar insertion, Gallstones, Laparoscopy, Pneumoperitoneum.

World Journal of Laparoscopic Surgery (2020): 10.5005/jp-journals-10033-1413
\end{abstract}

\section{INTRODUCTION}

Insertion of the primary trocar and successful creation of a pneumoperitoneum are essential steps in laparoscopic surgery, as more than $50 \%$ of complications during laparoscopic surgery occur at the time of Veress needle (VN) or the first trocar entry, independent of the complexity of surgery. ${ }^{1-3}$

Bateman et al. ${ }^{4}$ reviewed data on 2,324 laparoscopic procedures that were performed by the same surgical team and reported that more complications occurred during $\mathrm{VN}$ and trocar insertion than during the operative procedures that were performed. Therefore, optimizing the entry technique is essential. Techniques that are currently used for laparoscopic entry are VN, open laparoscopy (Hasson's technique), optical trocar, threaded or radially expanding devices, and direct first trocar insertion (DFTI) without a prior pneumoperitoneum. ${ }^{5}$ The existence of many laparoscopic entry techniques indicates that none has completely been established as standard or complication-free ${ }^{6}$ or they are equally highly effective.

Laparoscopic entry and creation of a pneumoperitoneum with a VN may be associated with complications such as extraperitoneal insufflation, which increase the difficulty and time of the procedure. ${ }^{7}$ A meta-analysis performed by Jiang et al. ${ }^{7}$ reported that the VN technique was associated with a significantly increased risk of minor complications. Additionally, the possibility of multiple insertion attempts and entry failure were significantly higher in the VN technique than in other techniques. ${ }^{8}$ Despite being considered safe by some laparoscopic surgeons, the VN technique may cause
Department of Surgery, College of Medicine, University of Wasit, Kut, Wasit, Iraq

Corresponding Author: Jawad K Shunayeh AL-Dhahiry, Department of Surgery, College of Medicine, University of Wasit, Kut, Wasit, Iraq, Phone: +9647801293684, e-mail: jawaddhahiry@gmail.com

How to cite this article: AL-Dhahiry JKS. Laparoscopic Entry Using Direct First Trocar Insertion without a Prior Pneumoperitoneum: A Prospective Cohort Study. World J Lap Surg 2020;13(3):108-112.

Source of support: Nil

Conflict of interest: None

serious vascular and visceral abdominal injuries, usually in obese patients and those with intra-abdominal adhesions. ${ }^{9}$

Hasson's open laparoscopic technique reduces vascular injuries but does not reduce bowel injuries. ${ }^{10}$ This may reflect a selection bias because Hasson's technique may be used in high-risk patients for visceral and vascular injuries. ${ }^{10}$ The DFTI technique was reported to be associated with low complication rates and is preferred by some laparoscopic surgeons. ${ }^{11}$

The DFTI technique without a prior pneumoperitoneum for laparoscopic entry was first reported by Dingfelder in $1978 .{ }^{12}$ The reported benefits of this technique are its short laparoscopic entry, short insufflations and operative times, ability to immediately recognize vascular and visceral injuries, minimal entry failure, and low carbon dioxide $\left(\mathrm{CO}_{2}\right)$ embolism. ${ }^{1,13}$

(0) The Author(s). 2020 Open Access This article is distributed under the terms of the Creative Commons Attribution 4.0 International License (https://creativecommons. org/licenses/by-nc/4.0/), which permits unrestricted use, distribution, and non-commercial reproduction in any medium, provided you give appropriate credit to the original author(s) and the source, provide a link to the Creative Commons license, and indicate if changes were made. The Creative Commons Public Domain Dedication waiver (http://creativecommons.org/publicdomain/zero/1.0/) applies to the data made available in this article, unless otherwise stated. 
Jansen et al. ${ }^{6}$ found that $57 \%$ of complications occurred during the insertion of the first trocar, and $43 \%$ of these complications were related to surgical experience. Failure to create and maintain a pneumoperitoneum may influence these complications.

Günenç et al. ${ }^{11}$ reported that VN and DFTI are blind techniques and can result in severe visceral and vascular injuries. To avoid such injuries, laparoscopic surgeons and gynecologists seek safe and effective laparoscopic access techniques. DFTI without a prior pneumoperitoneum was reported to be a safe alternative to the VN technique. ${ }^{14}$

Direct first trocar insertion is not contraindicated in thin or obese patients in non-emergency situations. ${ }^{15}$ Although it is a blind technique, DFTI decreases the number of blind steps from three steps with VN (insertion, insufflation, and trocar insertion) to one. The most important advantage of the DFTI technique is that it can be used to prevent complications associated with the use of a VN, such as failure of the pneumoperitoneum, extraperitoneal insufflation, bowel insufflation, and $\mathrm{CO}_{2}$ embolism. $^{16}$ The experience of the surgeon determines whether laparoscopic access can successfully be achieved, not $\mathrm{CO}_{2}$ pneumoperitoneum or trocars. ${ }^{17}$ A controllable, easy-to-follow technique and the surgeon's experience are more reliable factors than any design of the surgical instrument.

The DFTI technique is faster than other techniques for laparoscopic entry; ${ }^{18}$ however, it is the least-used technique in laparoscopic surgery today. ${ }^{19}$ The insufflation-related complications of DFTI technique are low and should be evaluated further. ${ }^{20}$

This study reported the 6.5-year experience of one consultant laparoscopic surgeon who routinely uses the DFTI technique without a prior pneumoperitoneum for laparoscopic entry. In particular, the safety, feasibility, complications, DFTI with $\mathrm{CO}_{2}$ insufflation time, and operative time during laparoscopic surgery were assessed.

\section{Materials and Methods}

\section{Ethical Considerations}

This study was approved by the ethics committee of the Medical College of Wasit University, Iraq, in March 2011. All enrolled patients were informed of the procedure and its potential complications and provided written informed consent prior to inclusion in the study.

\section{Study Design, Setting, and Participants}

This prospective cohort study enrolled 687 patients who underwent different laparoscopic procedures using the DFTI technique. Patients with an umbilical hernia, pregnant women, those with previous laparotomy incisions other than a gridiron incision for appendectomy, and those with a Pfannenstiel incision for obstetric and gynecologic pathologies were excluded. Three patients underwent conversion to the VN technique due to failure of the DFTI technique and were excluded from the analysis.

This study was performed at the Al-Karama Teaching Hospital, College of Medicine, Wasit University, Iraq, from April 2011 to December 2017. Routine investigations, including abdominal ultrasonography, chest radiography, electrocardiography, complete blood count, blood type, fasting blood sugar level, blood urea, Hepatitis B, and Hepatitis C, were performed. Antithrombotic measures such as subcutaneous heparin (the prophylactic dose was administered according to the patient's body mass index) and elastic stockings were used in obese and high-risk patients. All 687 operations were laparoscopically performed by one consultant laparoscopic surgeon using DFTI without a prior pnuemoperitoneum. Data on age, sex, indications for laparoscopic surgery, DFTI-related complications, complications that were unrelated to DFTI, DFTI- $\mathrm{CO}_{2}$ insufflation time, and operative time were recorded.

\section{Direct First Trocar Insertion Technique}

Each patient was placed in the supine position. After anesthesia was induced, he or she was then prepared and draped. A transverse 1-centimeter infraumbilical incision was made using a scalpel gauge 11 ( Demotek manufactured by Demophorius Healthcare Ltd, Cambridge,United Kingdom). In obese patients prepared for laparoscopic cholecystectomy (LC), the incision was made $3-4 \mathrm{~cm}$ above the umbilicus. The operating surgeon and his well-trained assistant elevated the anterior abdominal wall by pulling it up with their left hands. While elevating the anterior abdominal wall away from the underlying viscera, the surgeon held a $10-\mathrm{mm}$ trocar, with his right index finger positioned $3 \mathrm{~cm}$ away from the trocar tip to guard against sudden uncontrolled entry of the trocar into the abdomen. The trocar was inserted at a $45^{\circ}$ angle in non-obese patients and at a $90^{\circ}$ angle in obese patients. Then, the trocar was advanced in a controlled fashion into the peritoneal cavity with a twisting, semicircular motion. In contrast to the insertion of a VN, during which the surgeon can feel penetration through the fascia and peritoneum separately, during DFTI, a distinct single "pop" signified that the trocar had pierced the fascia and peritoneum. Then, a laparoscope was introduced, proper intraperitoneal placement was ascertained, and a pneumoperitoneum was created with high-flow insufflation. Then, the patient was tilted into the reverse Trendelenburg's position. Intraperitoneal placement of the first trocar was determined by observing the initial gas flow pressure rates. The intraperitoneal structures were carefully inspected for any injury or incidental pathology. Other trocars were inserted under direct vision. ${ }^{2,7,9,15}$

\section{Statistical Analysis}

This study's data were statistically analyzed using IBM SPSS Statistics V22.0 (IBM Corp., Armonk, N.Y., USA.). A $p$ value $<0.05$ was considered statistically significant.

\section{Results}

A total of 684 patients (age range: $16-77$ years; mean: mean \pm standard deviation: $39.21 \pm 12.04$ years; $95 \%$ confidence interval: 38.31-40.12 years) had successful DFTI entry. A total of 594 (86.8\%) women and 90 (13.2\%) men underwent different laparoscopic procedures. There were no major complications or deaths (Table 1). The pathologic distribution of the laparoscopic procedure is presented in Table 2.

DFTI-related complications occurred in nine (1.31\%) patients, including seven (1.02\%) patients with extraperitoneal $\mathrm{CO}_{2}$ insufflation. These patients were all women, possibly due to the fact that Camper's fascia is thicker in women than in men. Two patients ( $0.3 \%$; one man, one woman) had bleeding at the infraumbilical port site. The bleeding stopped spontaneously in both patients.

Regarding complications unrelated to DFTI, one woman developed a hernia; 10 patients (1.46\%) (three men and seven women) developed intraoperative bleeding at Calot's triangle unrelated to DFTI, which spontaneously stopped; and 14 patients (2.04\%) ( 2 men and 12 women) developed port-site infections that were conservatively treated (Table 3 ). 
Table 1: Patient demographics

\begin{tabular}{|c|c|c|c|c|c|c|c|}
\hline \multirow[b]{3}{*}{ Sex } & \multirow[b]{3}{*}{ No. } & \multirow[b]{3}{*}{$\%$} & \multicolumn{5}{|c|}{ Age at statistical analysis/Year } \\
\hline & & & \multirow[b]{2}{*}{ Mean $\pm S D$} & \multicolumn{2}{|c|}{ 95\% confidence interval } & \multirow[b]{2}{*}{ Range } & \multirow[b]{2}{*}{$p$ value } \\
\hline & & & & Lower boundary & Upper boundary & & \\
\hline Male & 90 & 13.2 & $46.01 \pm 12.62$ & 43.37 & 48.65 & $20-77$ & 0.00 \\
\hline Female & 594 & 86.8 & $38.18 \pm 11.62$ & 37.25 & 39.12 & 16.75 & \\
\hline Total & 684 & 100.0 & $39.21 \pm 12.04$ & 38.31 & 40.12 & 16.77 & \\
\hline
\end{tabular}

$\mathrm{SD}$, standard deviation

Table 2: Pathologic distribution of the study patients

\begin{tabular}{|c|c|c|c|c|}
\hline \multirow[b]{2}{*}{ Pathology } & \multicolumn{2}{|c|}{ Sex } & \multirow[b]{2}{*}{ Total } & \multirow[b]{2}{*}{$\%$} \\
\hline & Male & Female & & \\
\hline Chronic calculous cholecystitis & 43 & 509 & 552 & 80.7 \\
\hline Acute calculous cholecystitis & 14 & 25 & 39 & 5.7 \\
\hline Chronic acalculous cholecystitis & 4 & 7 & 11 & 1.6 \\
\hline Empyema of the gallbladder & 10 & 15 & 25 & 3.64 \\
\hline Mucocele I of the gallbladder & 12 & 18 & 30 & 4.40 \\
\hline Acute appendicitis & 4 & 7 & 11 & 1.6 \\
\hline Ovarian pathology & 0 & 4 & 4 & 0.6 \\
\hline Abdominal trauma & 3 & 4 & 7 & 1.03 \\
\hline Others* & 0 & 5 & 5 & 0.73 \\
\hline Total & 90 & 594 & 684 & 100 \\
\hline
\end{tabular}

*Two women, migrating intrauterine device; three patients, acute mesenteric lymphadenopathy

Table 3: Perioperative complications during the study period

\begin{tabular}{lllllll}
\hline & & \multicolumn{3}{c}{ Sex } & & \\
\cline { 3 - 5 } Complications & & Male & Female & Total & $\%$ & pvalue \\
\hline DFTI-related complications & Extraperitoneal insufflation & 0 & 7 & 7 & 1.02 & 0.179 \\
& Port-site bleeding & 1 & 1 & 2 & 0.3 & \\
& Vascular injury & 0 & 0 & 0 & 0 & \\
& Visceral injury & 0 & 0 & 0 & 0 & \\
Total & & 1 & 8 & 9 & 1.31 & \\
DFTI non-related complications & Hernia & 0 & 1 & 1 & 0.15 & 0.442 \\
& DFTl-unrelated intraoperative & 3 & 7 & 10 & 1.46 & \\
& bleeding & & & & & \\
Total & Port-site infection & 2 & 12 & 14 & 2.04 & \\
\hline
\end{tabular}

Table 4: Direct first trocar insertion (DFTI)- $\mathrm{CO}_{2}$ insufflations time and intraperitoneal operative time

\begin{tabular}{|c|c|c|c|c|c|c|c|c|}
\hline \multirow[b]{2}{*}{ Time (minute) } & & \multirow[b]{2}{*}{ No } & \multirow[b]{2}{*}{ Mean $\pm S D$} & \multicolumn{2}{|c|}{ 95\% confidence interval for mean } & \multirow[b]{2}{*}{ Minimum } & \multirow[b]{2}{*}{ Maximum } & \multirow[b]{2}{*}{$p$ value } \\
\hline & & & & Lower boundary & Upper boundary & & & \\
\hline \multirow[t]{3}{*}{ DFTI- $-\mathrm{CO}_{2}$ insufflations time } & Male & 90 & $2.32 \pm 0.57$ & 2.20 & 2.40 & 1.00 & 4.00 & 0.03 \\
\hline & Female & 594 & $1.89 \pm 0.53$ & 1.85 & 1.93 & 1.00 & 5.00 & \\
\hline & Total & 684 & $1.95 \pm 0.56$ & 1.90 & 1.99 & 1.00 & 5.00 & \\
\hline \multirow[t]{3}{*}{ Operative time } & Male & 90 & $35.92 \pm 9.73$ & 33.88 & 37.96 & 18.00 & 70.00 & 0.03 \\
\hline & Female & 594 & $30.82 \pm 7.60$ & 30.21 & 31.43 & 18.00 & 70.00 & \\
\hline & Total & 684 & $31.49 \pm 8.09$ & 30.88 & 32.10 & 18.00 & 70.00 & \\
\hline
\end{tabular}

The mean \pm standard deviation of the DFTI- $\mathrm{CO}_{2}$ insufflation times were $2.32 \pm 0.57 \mathrm{~m}, 1.89 \pm 0.53 \mathrm{~m}$, and $1.95 \pm 0.56 \mathrm{~m}$ for men, women, and all patients, respectively. The $95 \%$ confidence intervals were $2.20-2.40,1.85-1.93$, and 1.90-1.99 for men, women, and all patients, respectively. The mean \pm standard deviation operative time was $35.92 \pm 9.73 \mathrm{~m}, 30.82 \pm 7.60 \mathrm{~m}$, and 31.49 $\pm 8.09 \mathrm{~m}$ for men, women, and all patients, respectively. The $95 \%$ confidence intervals were $33.88-37.96,30.21-31.43$, and 30.88-32.10 for men, women, and all patients, respectively (all $p$ value $=0.03$; Table 4 ) 


\section{Discussion}

The aim of this study was to evaluate the safety, feasibility, complications, and time of performing the DFTI technique. DFTI has a very high feasibility rate, low complication rates, and less need for instrumentation, and a pneumoperitoneum can be created quickly. The DFTI technique is a safe alternative to the insertion of a VN and other laparoscopic entry techniques. However, performing the DFTI technique requires good experience.

Insertion of the first trocar and creation of a pneumoperitoneum are the most critical steps in laparoscopic surgery. Subcutaneous emphysema, port-site bleeding, and vascular and visceral intraperitoneal injuries are serious complications that may occur during laparoscopic entry and creation of a pneumoperitoneum. Four basic techniques are used for laparoscopic entry and to establish a pneumoperitoneum: blind VN, DFTI, insertion of an optical trocar, and open laparoscopy. ${ }^{2}$ The DFTI technique was first described by Dingfelder in $1978^{13}$ and later reported by Copeland et al. in 1983. ${ }^{21}$ The latter reported that adequate abdominal wall relaxation, a proper skin incision, and the use of a sharp trocar are essential for successfully performing DFTI; other authors advised elevating the rectus sheath for a successful outcome. ${ }^{15}$ Innovations in shielded trocars have encouraged use of DFTI, but no experimental or clinical study has established the superiority of the shielded trocar to the non-shielded trocar. ${ }^{1,21,22}$

The rationale for using the DFTI technique before the creation of a pneumoperitoneum is based on the fact that many complications that occur during laparoscopic surgery are directly related to the insertion of a VN. ${ }^{22,23}$ It was reported that the DFTI technique was a safe alternative to the VN technique. ${ }^{20,24}$ Additionally, the DFTI technique was associated with minimal insufflation-related complications such as gas embolism and was faster than most other laparoscopic entry techniques. ${ }^{20}$

Theodoropoulou et al. ${ }^{1}$ reported that the DFTI feasibility rate was $99.5 \%$, which was compatible with the feasibility rate that was found in this study. In a randomized, prospective study that enrolled 84 patients, Prieto-Diaz-Chavez et al. ${ }^{25}$ reported that the complication rates for DFTI and VN insertion were $2.3 \%$ and $23.8 \%$, respectively. Yerdel et al. ${ }^{24}$ enrolled 1,567 patients in their study and reported that the complication rates after DFTI and VN insertion were $0.9 \%$ and $14.4 \%$, respectively. In a study that included 698 thin and very obese patients, Agresta et al. ${ }^{26}$ found that DFTI was safe, with a slightly higher feasibility rate than the VN technique, and was related to minimal minor complication rates, but they reported that there were no differences in the rates of major complications. DFTI may be a safe technique in thin patients. ${ }^{26,27}$ The DFTI technique did not lead to major complications in this study. There were minor rates of DFTI-related and DFTI non-related complications. The total minor complication rate was significantly lower than that of $\mathrm{VN}$ as reported in previous studies. ${ }^{20,24,26}$

Byron et al. ${ }^{18}$ reported DFTI and VN insertion times of $2.2 \mathrm{~m}$ and $5.9 \mathrm{~m}$, respectively. Zakherah et al. ${ }^{28}$ reported DFTI and VN insertion times of $2.2 \pm 0.7 \mathrm{~m}$ and $8.2 \pm 1.4 \mathrm{~m}$, respectively. Thus, in this study, the DFTI- $\mathrm{CO}_{2}$ insufflation time was comparable with the DFTI time of these studies, ${ }^{18,27}$ but a pure DFTI time without a $\mathrm{CO}_{2}$ insufflations time was significantly shorter than that of the DFTI and $\mathrm{VN}$ insertion times.

Agresta et al. ${ }^{26}$ study showed that DFTI was feasible in $100 \%$ of cases, and conversion to open laparoscopy was not necessary.

Although the open trocar technique with Hasson's cannula is considered a safe alternative, it is not complication free and is a time-consuming entry technique; thus, many laparoscopic surgeons use it very selectively. ${ }^{16,26}$ Past studies ${ }^{16,22,26}$ revealed that none of the available techniques create a pneumoperitoneum during laparoscopic entry and is free of complications. Each was associated with different advantages and limitations when performed by experienced surgeons for appropriate indications. ${ }^{29}$ This study has some limitations that were:

- Unavailability of some laparoscopic instruments that can shorten the operative time such as multifire reusable clip applier and those instruments that can reduce the entry-related injuries such as the optical trocars.

- Poor quality of some laparoscopic instruments such as electrocautery hooks and graspers.

\section{Conclusion and Clinical Significance}

When performed by an experienced laparoscopic surgeon, DFTI is a safe, fast, and cost-effective technique for laparoscopic entry and pneumoperitoneum creation. Additionally, it has a very high feasibility rate, low complications, few instrumentation, and fast creation of pneumoperitoneum. Thus, DFTI technique is a safe alternative to VN insertion and other laparoscopic entry techniques. This study findings suggest that successful DFTI requires a good surgical experience. I recommend large-scale combined studies by the colleges of obstetricians and gynecologists and surgeons to assess laparoscopic entry, $\mathrm{CO}_{2}$-insufflation and operative times, and complication rates of the different laparoscopic entry techniques.

\section{References}

1. Theodoropoulou K, Lethaby DR, Bradpiece HA, et al. Direct trocar insertion technique: an alternative for creation of pneumoperitoneum. JSLS 2008;12:156-158.

2. Patel PG, Chikhalia DP, Patel R, et al. Direct trocar entry in laparoscopic surgeries: a retrospective study. Gastroenterol Hepatol J 2017;1:29-33.

3. Bathla V, Thekdi P, Koradia P, et al. Comparative study of modified open technique and closed technique for primary trocar insertion in laparoscopic surgery. Int J Res Med Sci 2016;4:160-164. DOI: 10.18203/2320-6012.ijrms20160024.

4. Bateman BG, Kolp LA, Hoeger K. Complications of laparoscopy, operative and diagnostic. Fertil Steril 1996;66(1):30-35. DOI: 10.1016/ S0015-0282(16)58383-6.

5. McKernan JB, Finley CR. Experience with optical trocar in performing laparoscopic procedures. Surg Laparosc Endosc Percutan Tech 2002;12(2):96-99. DOI: 10.1097/00129689-200204000-00004.

6. Jansen FW, Kapiteyn K, Trimbos-Kemper T, et al. Complications of laparoscopy: a prospective multicenter observational study. Br J Obstet Gynaecol 1997;104(5):595-600. DOI: 10.1111/j.1471-0528.1997. tb11539.x.

7. Jiang $X$, Anderson C, Schnatz PF. The safety of direct trocar versus veress needle for laparoscopic entry: a meta-analysis of randomized clinical trials. J Laparoendosc Adv Surg Tech A 2012;22(4):362-370. DOI: 10.1089/lap.2011.0432.

8. Ohlgisser M, Sorokin Y, Heifetz M. Gynecologic laparoscopy: a review article. Obstet Gynecol Surv 1985;40(7):385-396. DOI: 10.1097/00006254-198507000-00001.

9. Santala M, Järvelä I, Kauppila A. Transfundal insertion of a veress needle in laparoscopy of obese patients: a practical approach. Hum Reprod 1999;14(9):2277-2278. DOI: 10.1093/humrep/14.9.2277.

10. Jacobson MT, Osias J, Bizhang R, et al. The direct trocar technique: an alternative approach to abdominal entry for laparoscopy. JSLS 2002;6:169-174.

11. Günenç MZ, Yesildaglar N, Bingöl B, et al. The safety and efficacy of direct trocar insertion with elevation of the rectus sheath instead 
of the skin for pneumoperitoneum. Surg Laparosc Endosc Percutan Tech 2005;15(2):80-81. DOI: 10.1097/01.sle.0000162106.95875.b9.

12. Dingfelder JR. Direct laparoscopic trocar insertion without prior pneumoperitoneum. J Reprod Med 1978;21:45-47.

13. Catarci M, Carlini M, Gentileschi $P$, et al. Major and minor injuries during the creation of pneumoperitoneum: a multicenter study on 12,919 cases. Surg Endos 2001;15(6):566-569. DOI: 10.1007/ s004640000381.

14. Niraj NM, Gaikwad N. Direct trocar insertion: a safe laparoscopic access. Int J Gynecol Obstetr 2006;8(2):1-4.

15. Agresta F, Mazzarolo G, Bedin N. Direct trocar insertion for laparoscopy. JSLS 2012;16(2):255-259. DOI: 10.4293/108680812X134 27982376383.

16. Altun H, Banli O, Kavlakoglu B, et al. Comparison between direct trocar and Veress needle insertion in laparoscopic cholecystectomy. J Laparoendosc Adv Surg Tech A 2007;17(6):709-712. DOI: 10.1089/ lap.2006.0015.

17. Fuller J, Scott W, Ashar B, et al. Laparoscopic trocar injuries: a report from a U.S. Food and drug administration (FDA) center for devices and radiological health (CDRH) systematic technology assessment of medical products (STAMP) committee [US food and drug administration website]. 2005. 1-14. Available from: https://static1. squarespace.com/static/554b3088e4b0942ff6e52679/t/55776385e 4b09779d062a326/1433887621351/Laparoscopic+Trocar+Injuries++FDA+Report+2003.pdf.

18. Byron JW, Markenson G, Miyazawa K. A randomized comparison of veress needle and direct trocar insertion for laparoscopy. Surg Gynecol Obstet 1993;177:259-262.

19. Molloy D, Kaloo PD, Cooper M, et al. Laparoscopic entry: a literature review and analysis of techniques and complications of primary port entry. Aust NZJ Obstet Gynaecol 2002;42(3):246-254. DOI: 10.1111/j.0004-8666.2002.00246.x.
20. Vilos GA, Ternamian A, Dempster J, et al. Laparoscopic entry: a review of techniques, technologies, and complications. J Obstet Gynaecol Can 2007;29(5):433-447. DOI: 10.1016/S1701-2163(16)35496-2.

21. Copeland C, Wing R, Huka JF. Direct trocar insertion at laparoscopy: an evaluation. Obstet Gynecol 1983;62:655-659.

22. Jarrett 2nd JC. Laparoscopy: Direct trocar insertion without pneumoperitoneum. Obstet Gynecol 1990;75:725-727.

23. Philips PA, Amaral JF. Abdominal access complications in laparoscopic surgery. J Am Coll Surg 2001;192(4):525-536. DOI: 10.1016/S10727515(01)00768-2.

24. Yerdel MA, Karayalcin K, Koyuncu A, et al. Direct trocar insertion versus Veress needle insertion in laparoscopic cholecystectomy. Am J Surg 1999;177(3):247-249. DOI: 10.1016/S0002-9610(99)00020-3.

25. Prieto-Díaz-Chávez E, Medina-Chávez JL, González-Ojeda A, et al. Direct trocar insertion without pneumoperitoneum and the veress needle in laparoscopic cholecystectomy: a comparative study. Acta Chir Belg 2006;106(5):541-544. DOI: 10.1080/00015458.2006.11679948.

26. Agresta F, De Simone P, Ciardo LF, et al. Direct trocar insertion vs Veress needle in nonobese patients undergoing laparoscopic procedures: A randomized prospective single-center study. Surg Endosc 2004;18(12):1778-1781. DOI: 10.1007/s00464-004-9010-y.

27. Abbasoglu $O$, Tekant $Y$, Alper $A$, et al. Prevention and acute management of biliary injuries during laparoscopic cholecystectomy: expert consensus statement. Ulus Cerrahi Derg 2016;32(4):300-305. DOI: 10.5152/UCD.2016.3683.

28. Zakherah MS. Direct trocar versus veress needle entry for laparoscopy: a randomized clinical trial. Gynecol Obstet Invest 2010;69(4):260-263. DOI: 10.1159/000276571.

29. Woolcott R. The safety of laparoscopy performed by direct trocar insertion and carbon dioxide insufflation under vision. Aust N Z J Obstet Gynaecol 1997;37(2):216-219. DOI: 10.1111/j.1479-828X.1997. tb02257.x. 